\title{
Towards Simulation Aided Online Teaching: Material Design for Applied Fluid Mechanics
}

\author{
https://doi.org/10.3991/ijoe.v14i12.8630 \\ Gonca Altuger-Genc \\ Farmingdale State College, Farmingdale, NY, USA \\ gencg@farmingdale.edu \\ Yue Han \\ Le Moyne College, Syracuse, NY, USA \\ Yegin Genc \\ Pace University, New York, NY, USA
}

\begin{abstract}
Learning is shifting from synchronous in-class settings to asynchronous online platforms in an attempt to make education accessible to wider audience. However, certain vital components of engineering education, such as laboratory work and hands-on practices, are harder to conduct online. Understanding how technology can help offering such components online can impact the quality of online education a great deal. The goal of this study is to improve the effectiveness of online courses in engineering. Particularly, we aim to transform some of the hands-on practices that are fundamental for engineering education into online setting. We first explored existing literature and found that realtime experimentation can be carried out with the help of online modules. We then designed two simulations for a fluid mechanics lab. We expect these simulations to be used to support teaching and evaluation of fluid mechanics through various assignments that utilize these simulations. This study surveys how online modules have been studied in effort to relax the time and location constraints of inclass education. Drawing upon the literature review it proposes a novel approach to incorporate simulations to ground learning of abstract concepts such as buoyancy.
\end{abstract}

Keywords-Bernoulli's Equation, Buoyancy, Fluid Mechanics, Simulationbased Learning

\section{$1 \quad$ Introduction}

The demand for time and location independent education led higher education institutions to offer online courses, programs and degrees. Many institutions employ use of online learning platforms to support their in-person traditional courses. These platforms serve as an online platform where course instructor can share lecture slides, homework assignments, additional reading materials, course announcements and grades; hence making the course more accessible to students. Although incorporation 
of online course platforms is a great addition to the traditional learning settings, they don't fully meet the need for time and location independent education. In an effort to meet the demand, many higher educational institutions started to offer online courses and degrees. One of the challenges that instructors came across was to offer the courses that have a laboratory or hands-on component, in an online setting. To address this challenge, many educators from different institutions and different fields redesigned their laboratories to be offered either remotely, through a simulation or animation (interactive or non-interactive) by developing virtual laboratories. Ma et al. [12] presented a comparative review of the hands-on, simulation-based and remote laboratories; of the 60 papers that were considered, 39 papers belonged to the fields of engineering subjectwise and 32 papers belonged to the fields of engineering methodology-wise. Fabregas et al. [1] presented the development of interactive online laboratories for a control course; where Simulink and Easy Java simulations were used to develop the remote laboratories. Fiore and Ratti [2] discussed the remote laboratory concept from the realtime availability of the experiment; where learners can see the experiment field in realtime through a continuous video stream. Canfora et al. [3] highlighted the challenges of traditional laboratory as the need for continuous upgrade and the costs associated with that and presented a remotely accessible laboratory. Yeung and Huang [4] presented the development of a remote-access lab for control experiments where they focused on the security and stability of the system. Klein and Wozny [6] emphasized accessibility as one of the advantages of remote laboratories and presented a remote laboratory for an ethanol-water distillation column for chemical engineering education. Jara et al. [7] presented a "blended-learning" environment, where students completed a portion of the laboratory hands-on in the class and completed the practice exercises remotely outside of the class. Prada et al. [8] shared a remote laboratory set-up for automatic control and emphasized the importance of seamless integration of the hardware and software as an important challenge for remote laboratories. Colwell et al. [9] discussed the "PEARL - The Practical Experimentation by Accessible Remote Learning" project, where a platform for remote experimentation is designed to provide extended access and availability to science and engineering courses in four different institutions. Scanlon et al [10] further presented the "PEARL" platform and concluded that the platform provided an improved experience in laboratory experiments for students with disabilities. Corter et al. [11] examined the learning outcomes from remote, simulation-based and hands-on student laboratories on "effectiveness of the lab formats", "satisfaction with the lab formats" and "data collection mode", the outcomes showed that students' satisfaction with the lab formats may be influenced by the degree of technology incorporated within that format. Esche et al. [5] presented the development of system architecture for remote experimentation, where the pilot implementation results confirmed the remote experimentation was as effective as hands-on experimentation. Nickerson et al. [27] presented a model to test "educational effectiveness" of remotely accessible laboratories; where a vast majority of students rated the remote laboratories as or more effective than hands-on traditional laboratories. Based on the results of many studies, it can be concluded that real-time experimentation is an important part of remote laboratories, and remote settings may help defer some of the costs associated with the traditional laboratories. With a seamless set-up, remote 
laboratories can be as effective as the hands-on laboratories. Remote laboratories also provided increased accessibility for students with disabilities. These outcomes make implementation of remote laboratories a necessary component for online education, and a very effective platform for the traditional education.

In addition to remote laboratories, simulation-based learning platforms are also commonly used to support and complement the learning in online courses. Davidovitch et al. [20] examined the incorporation of simulation-based learning components when teaching engineering project management. Stephens et al. [21] examined the incorporation of simulations in high school and "investigated student interactions with simulations" in whole classroom and small group settings. Rafael et al. [22] provided an overview of a case study, where students can $\log$ in remotely to the web site to set up the simulation parameters and run on-line simulations, where MATLAB platform was used to develop the computational platform. Jara et al. [23] presented the use of "Easy Java Simulations (EJS)", a java-based collaboration tool, where a synchronous collaboration platform is created. Dalgarno et al. [24] presented the use of virtual laboratories as a resource to be used as a preparation for the laboratory experiences; it is concluded that the pre-laboratory preparation simulations increase students' familiarity with the laboratory equipment and increase students' confidence in the laboratory.

Lei et al. [26] presented the development of a remote experiment on "fatigue test of drive axle", where VRML, JavaScript and 3DSMAX programming languages and graphic animation software is used to develop the virtual interface.

Following the remote laboratory concept, many institutions started to develop virtual laboratories. Some institutions replaced their traditional hands-on laboratory settings with fully virtual laboratory settings. Tatli et al. [13] provided a review of virtual laboratories used in chemistry education; where it was concluded that, in virtual laboratories students focus on the process of the experiment whereas in traditional setting students focus on the laboratory equipment and tools. Grimaldi et al. [14] examined the architecture and delivery of virtual laboratories where the "delivered services" can range from students watching online how the teacher controls the equipment, to students remotely creating the experiment with the specialized software. Although the levels of students' involvement in the virtual laboratories varies, most of the times students' involvement is limited to setting up and running the simulation to collect data. Shin et al. $[15,21]$ discussed the computer-based education systems and provided an overview of the development approach for a virtual laboratory setting where a virtual setting will overcome "space and time limitations, experiment related hazards and safety concerns". Virtual laboratories and virtual experimental setups provided solutions to another challenge of the cost of setting up a physical laboratory space. Guggisberg et al. [16] presented the project "NANO-WORLD" where complexity, cost and rarity of teaching using a Real-life nanotechnology laboratory is addressed by developing a "Virtual Nanoscience Laboratory". Quesnel et al. [17] focused on the interdisciplinary nature of "Environmental Sciences" where the challenge is to "perform experiments on natural systems", as it is not always possible to run replications of experiments. Kara et al. [18] examined the sustainability of "Virtual and Remote Laboratories (VRL)" considering possible technological and pedagogical issues, and examined "maintenance and expendability" of VRL considering technical issues and user 
profiles. Chen [19] presented the challenge of virtual laboratories presenting an "oversimplified view of scientific inquiry", which may not cultivate scientific inquiry and reasoning. Brinson [25] presented a review of virtual and remote laboratories versus traditional laboratories where the learning outcomes such as "Knowledge \& Understanding", "Inquiry Skills", "Practical Skills", "Perception", "Analytical Skills", "Social \& Scientific Communication"; it was concluded that virtual and remote laboratories provide same or higher results in all learning outcomes than the traditional laboratories.

The review of the available resources on remote laboratories, virtual laboratories and online simulation-based platforms revealed that selection of the right approach is a major challenge in implementing an online course. In addressing this challenge two key criteria were considered: the cost of the technology [33] and the accessibility and userfriendliness of the technology, respectively. The cost of the technology can be defined as the cost of the software and hardware as well as cost of the personnel to create codes, algorithms, to set-up experiments and prepare learning materials. Accessibility and user-friendliness can be defined based on student experience. Difficulty may be experienced with platforms that would require students to download software or crate an account to complete the assignments; as these requirements may result in technical difficulties and can be frustrating for students who are trying to access the course materials.

To overcome these aforementioned challenges, Scratch software, developed by MIT Media Lab is selected to develop simulations for the online Applied Fluid Mechanics course. Scratch is a free platform to develop and access the animations and simulations. In addition, Scratch platform doesn't require an account to be created to run the simulations. An account is only needed to develop the simulations. So students who are trying to access course simulations simply needs to follow the simulation link, making it easier for them to complete the simulations.

This study will provide the design and development process for two interactive simulations: buoyancy simulation and inclined pipe simulation, respectively along with examples of possible assignments that can accompany these interactive simulations. The paper is structured as follows: a general course description will be provided followed by a description and development of each simulation and possible assignments that can be tied to the simulations, and how the scratch platform is used in developing these simulations.

\section{General Course Description}

The Applied Fluid Mechanics course is a 3-credit sophomore level course and is a required course for the Mechanical Engineering Technology A.A.S, B.S., and Industrial Technology - Facility Management Technology B.S. degree programs. The course is offered in-class and online. Both the in-class and the online offerings of the course follow a designated textbook "Applied Fluid Mechanics" by Mott and Untener [28]. In the in-class offering of the course, students have weekly homework assignments, 2 quizzes, 1 mid-term exam and 1 final exam. In the online offering, the course material is offered in modules. Each module is 2 weeks long and covers 2 chapters from the 
textbook. Each module has lecture slides, reading assignments from the textbook, and homework assignment, module review question assignment, discussion question assignment and quiz. In addition, the online offering has 1 mid-term exam and 1 final exam.

The on-line offering of the course brings the challenge of successfully conveying the theory of the important concepts in an online environment. In an effort to overcome that challenge, initially three simulations have been developed to cover the concepts of viscosity and falling ball viscometer, the continuity equation, and pressure management in fluids. These online simulations have been developed using an open-source platform, Scratch [29, 30]. "Scratch is developed by the Lifelong Kindergarten Group at the MIT Media Lab. See http://scratch.mit.edu". These online simulations, accompanied with assignments, have been implemented to the Applied Fluid Mechanics course during Fall 2014 semester to support the theory learnt in the course [31]. The development process of these simulations and the pilot implementation process are reported in a previous study [32]. The pre-experience survey administered prior to the pilot implementation process concluded that $90 \%$ of the students considered themselves as technology-forward and preferred simulations to be included in their courses. The pilot implementation simulations were offered as optional extra credit assignments. Based on the student feedback, additional simulations were developed to teach the concepts of buoyancy and inclined-pipes. The pilot implementation showed that [32] the online simulations are a valuable addition to the course.

This study discusses the design and development of two new simulations to be implemented to the Applied Fluid Mechanics course.

\section{Development of Online Simulations and Accompanying Assignments}

The two online simulations are developed using the Scratch [30] platform. The first simulation, Buoyancy Simulation, demonstrated the concept of buoyancy and buoyant force. The second simulation, Bernoulli's Equation Simulation, demonstrates the concept of conservation of energy and Bernoulli's equation and it's relation to fluid flow rate using an inclined pipe set-up.

\subsection{Buoyancy Simulation}

The buoyancy simulation reviews the concepts of buoyancy and buoyant force and reinforces these concepts with the interactive style of the simulation set-up. The simulation is designed to have a container filled with a fluid and a box, which is being held within the fluid with a rope. On the right side of the container, there are three weights with three different sizes and numbered as 1, 2, and 3. The initial set-up of the Buoyancy simulation is shown in Figure 1. 


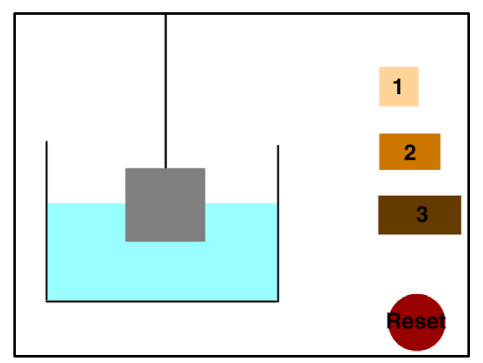

Fig. 1. Buoyancy Simulation Set-Up

Using the online simulation set-up, students can run three versions of the experiment. In the first version, students can select weight 1 from the right-hand side. Upon selection, this weight will be added on the box that is held with a rope in the fluid. Students will also observe that the portion of the box that is outside of the fluid decreases as weight 1 is added, shown in Figure 2. In the second version of the experiment, students can select weight 2 , and this weight will be added on the box that is held with a rope in the fluid. Students will observe that the box that is held with the rope is now almost fully submerged in the fluid, shown in Figure 3. In the third version of the experiment, students can select weight 3 , and this weight will be added on the box that is held with a rope in the fluid. Students will observe that the box and a portion of weight 3 will be submerged in the fluid, as shown in Figure 4.

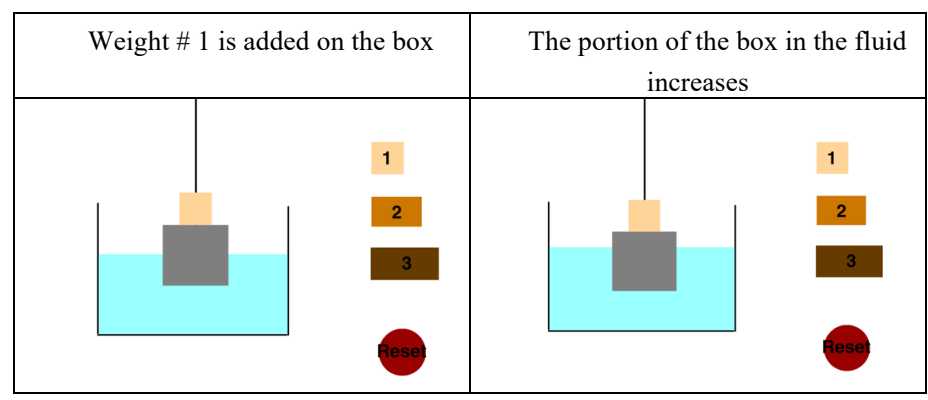

Fig. 2. Buoyancy Simulation - Weight 1 Added

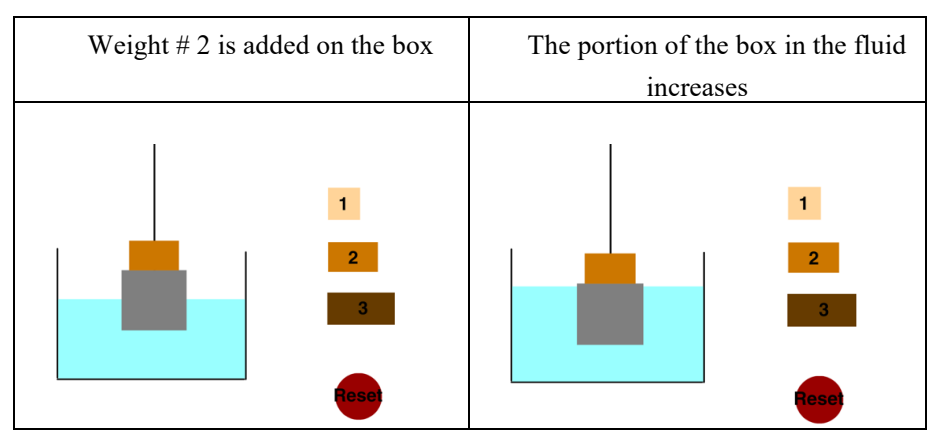

Fig. 3. Buoyancy Simulation - Weight 2 Added 


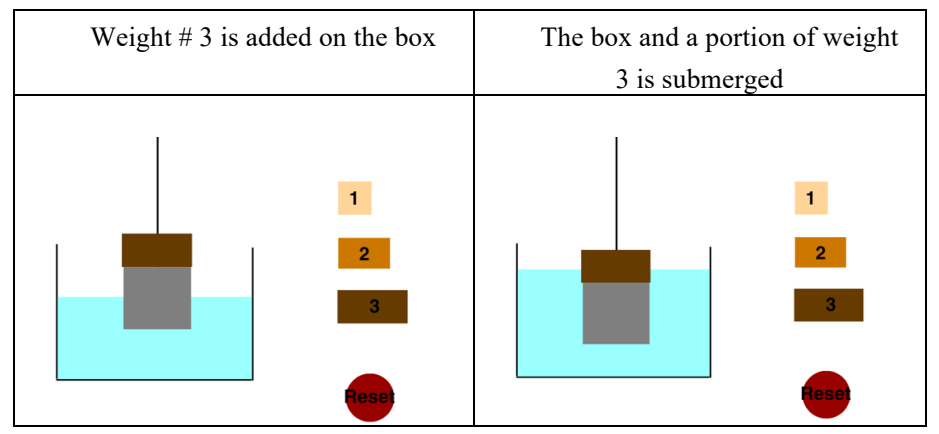

Fig. 4. Buoyancy Simulation - Weight 3 Added

\subsection{Buoyancy Simulation Assignments}

The simulations are designed to support the in-class learning and also provide a visual overview of the concepts learnt in the course. The online nature of the simulations allows students to run the simulations as many times as they want and whenever they want.

In an effort to support the in-class learning, simulations can be paired up with assignments or questions to help students use the theory and equations learnt in class. Table 1 provides a summary of the sample assignments that can be given to the students.

Table 1. Sample Assignments for Buoyancy Simulation

\begin{tabular}{|c|c|c|}
\hline & Question & Students Will \\
\hline 1 & $\begin{array}{l}\text { Please add weight } 1 \text { on the box and calculate } \\
\text { the magnitude of the buoyant force acting on } \\
\text { the box and weight. The box, weight and rope } \\
\text { tension is given }\end{array}$ & $\begin{array}{l}\text { 1. Run the simulation by adding } \\
\text { weight } 1 \\
\text { 2. Develop the free body diagram } \\
\text { 3. Employ Newton's Second Law to } \\
\text { calculate the Buoyant Force }\end{array}$ \\
\hline 2 & $\begin{array}{l}\text { Please add weight } 2 \text { on the box and calculate } \\
\text { the magnitude of the tension force on the } \\
\text { rope. Weight } 2 \text { is given and the Buoyant } \\
\text { Force is given. }\end{array}$ & $\begin{array}{l}\text { 1. Run the simulation by adding } \\
\text { weight } 2 \\
\text { 2. Develop the free body diagram } \\
\text { 3. Calculate the total weight } \\
\text { 4. Compute the Tension on the rope }\end{array}$ \\
\hline 3 & $\begin{array}{l}\text { Please add weight } 3 \text { on the box and calculate } \\
\text { the magnitude of the buoyant force. The } \\
\text { weight of the box that is held with the rope is } \\
\text { given. Weight } 3 \text { dimensions are given. The } \\
\text { tension on the rope is given. }\end{array}$ & $\begin{array}{l}\text { 1. Run the simulation by adding } \\
\text { weight } 3 \\
\text { 2. Develop the free body diagram } \\
\text { 3. Calculate the total weight } \\
\text { 4. Compute the buoyant force }\end{array}$ \\
\hline
\end{tabular}

The assignments shown in Table 1 are a sample of assignments that can be created and implemented in a fluid mechanics course. Course instructor has the flexibility to change the fluid type, the buoyant force value, tension value, and the size of the box and the sizes of the weights. Through the completion of these and additional assignments, students will gain experience in free body diagram development and solving 
different types of buoyancy problems. An overview of the solution process for assignment 2 is shown in Figure 5 as an example.

\begin{tabular}{|c|c|}
\hline $\begin{array}{c}\text { Free Body Diagram De- } \\
\text { velopment }\end{array}$ & Mathematical Equation Set Up \\
\hline Tension $\uparrow$ & $\begin{array}{c}\text { Total Force }=0 \\
\text { Tension }+ \text { Buoyant Force }- \\
\text { Weight }=0\end{array}$ \\
\hline $\begin{array}{c}\text { Buovant } \\
\text { Forre }\end{array}$ & \\
\hline
\end{tabular}

Fig. 5. Solution Overview for Buoyancy Assignment

\subsection{Inclined Pipe Bernoulli's Equation}

The Bernoulli's Equation represents the concept of conservation of energy in fluid mechanics. The set-up demonstrates the Bernoulli's Equation concept through an inclined pipe with changing diameters. For the set-up there are two pressure gages attached to the system and measures the Point 1 and Point 2 pressures. The direction of the flow and the velocity of the flow are demonstrated by yellow balls moving within the pipe as shown in Figure 6. Although this study only presents and reports on the inclined Bernoulli's Equation simulation; the vertical pipe Bernoulli's Equation simulation has been developed and the results are reported on the development and pilot implementation outcomes [31,32].



Fig. 6. Bernoulli’s Equation Inclined Pipe

Using the online simulation set-up students can run the inclined pipe Bernoulli's Equation simulation as many times as they need. Once students start running the simulation they will see the yellow balls moving from the larger diameter section of the pipe to the smaller diameter section of the pipe. Students can observe the change in the velocity from larger diameter portion of the pipe to the smaller diameter portion of the pipe by monitoring the yellow balls. The online simulation stages for the vertical set-up and for the inclined set-up are shown in Figure 7. 


\begin{tabular}{|l|l|}
\hline Step 1: Simulation Starts & Step 2: Simulation Starts Running \\
\hline Step 3: The velocity change is observed & Step 4: Simulation Runs Continuously \\
\hline
\end{tabular}

Fig. 7. Representation of Bernoulli's Equation Inclined Pipe

\subsection{Inclined Pipe Bernoulli's Equation Simulation Assignments}

The Bernoulli's Equation Simulations are designed to support the in-class learning as well as to provide students a hands-on and visual animation they can employ to understand the theory better. In the inclined pipe set-up assignment, 2 questions are developed. Table 2 provides a summary of the assignments for the inclined pipe set-up.

Table 2. Sample Assignments for Inclined Pipe - Bernoulli's Equation

\begin{tabular}{|c|c|c|}
\hline & Question & Students Will \\
\hline 1 & $\begin{array}{l}\text { Fluid is flowing in an inclined pipe as } \\
\text { shown in Figure } 7 \text {. The pressure at Point } \\
1 \text { pipe, Point } 1 \text { height, and the velocities } \\
\text { of flow in Points } 1 \text { and Point } 2 \text { are given. } \\
\text { Run the simulation and calculate the } \\
\text { pressure in the smaller diameter portion } \\
\text { of the pipe. }\end{array}$ & $\begin{array}{l}\text { 1. Run the simulation and observe the sys- } \\
\text { tem for the inclined pipe set-up. } \\
\text { 2. Identify the known and unknown com- } \\
\text { ponents of the Bernoulli's Equation } \\
\text { 3. Use Bernoulli's Equation to solve for } \\
\text { the pressure in the smaller diameter por- } \\
\text { tion of the vertical pipe }\end{array}$ \\
\hline 2 & $\begin{array}{l}\text { Fluid is flowing in an inclined pipe as } \\
\text { shown in Figure } 7 \text {. The pressures and di- } \\
\text { ameters at Point } 1 \text { and Point } 2 \text { are given. } \\
\text { The elevation difference between the two } \\
\text { points are given. Run the simulation and } \\
\text { calculate the velocity of the flow in the } \\
\text { smaller diameter portion of the pipe. }\end{array}$ & $\begin{array}{l}\text { 1. Run the simulation } \\
\text { 2. Identify the known and unknown com- } \\
\text { ponents of the Bernoulli's Equation } \\
\text { 3. Use the Continuity Equation to deter- } \\
\text { mine the relationship between the diam- } \\
\text { eter and velocity } \\
\text { 4. Use Bernoulli's Equation to solve for } \\
\text { the velocity in the smaller diameter por- } \\
\text { tion of the vertical pipe }\end{array}$ \\
\hline
\end{tabular}

The assignments shown in Table II are some examples of the possible in-class and homework style assignments that can be used with the inclined pipe Bernoulli's Equation simulations. An overview of the system set-up for assignments in Table II is shown in Figure 8. 


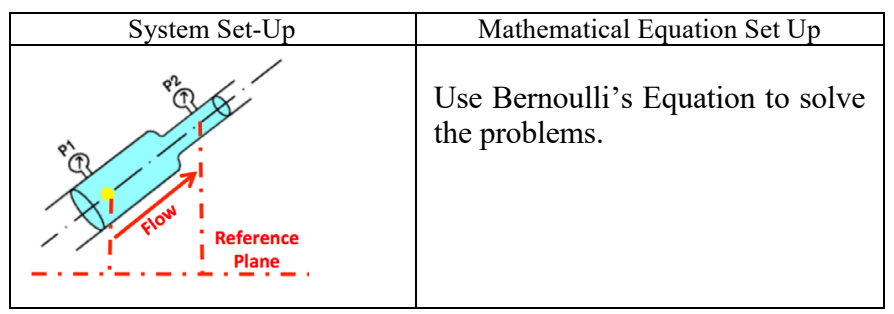

Fig. 8. System Set-up for Bernoulli’s Equation Assignment

\subsection{Proposed Evaluation Process for the Simulation Assignments}

To proposed evaluation process has two levels: an assignment level and a course level. The assignment level evaluation is to assess the effectiveness of the simulations on students' learning. Faculty will grade the submissions and provide feedback to the students. The course level evaluations are to assess the effectiveness of the simulations on students' engagement. A question will be added to the course evaluation survey to learn about students' experience and if the simulations were helpful in understanding the subject.

\section{Building the Simulations Using Scratch Platform}

\subsection{Scratch Platform}

Scratch is a visual programming language created by MIT Media Lab Lifelong Kindergarten Group. In the Scratch online community, users can create projects using the Scratch language. The user interface of Scratch development environment is shown as in Figure 9. Users can drag coding blocks from the Blocks Palette and stack them on the right area in the user interface to create the commands for a sprite, which is the carton cat shown on the left. Most of the elements in this interface are changeable and can be user-generated: users can select pre-existing pictures as a sprite or draw their own sprites; users can change or draw the stage backgrounds; users can also create and name their own blocks. Scratch users play with these elements to generate interesting projects including games, animations and simulations.

\subsection{Building the Buoyancy Simulation}

We followed a three-step process to build the buoyancy simulation. The first step is the concept design. We created hand drawn drafts to determine the main elements, conditions and effects for the simulation. Then we implemented the design in Scratch. In the final step, we tested the simulation and fixed all errors we have found. 


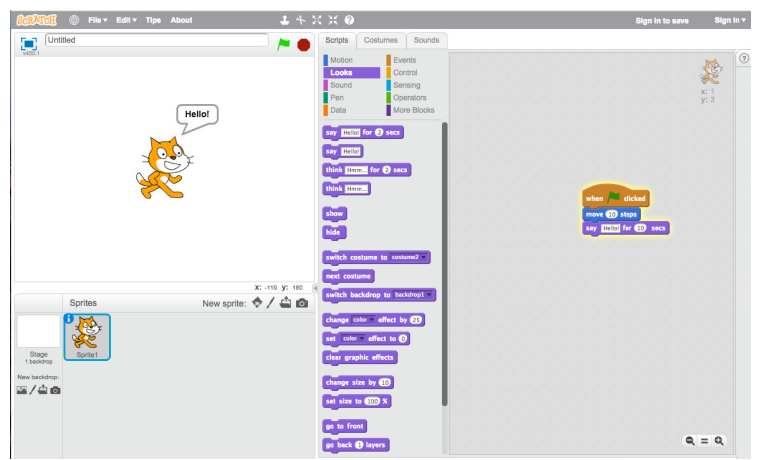

Fig. 9. Scratch Development Environment

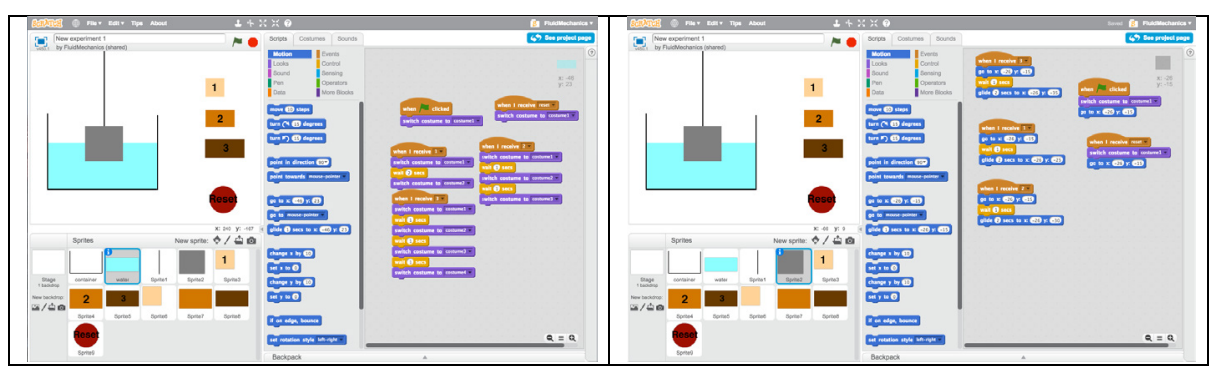

Fig. 10.Scratch Code for Buoyancy Simulation

This simulation is created in the form of animation. For each condition, a viewer can click on the weight and visualize all associated changes. The main elements were created as sprites shown in Figure 10. In this simulation, the changes of the boxes were mostly achieved via Motion blocks; meanwhile the changes of the fluid were implemented via Looks blocks. To increase the flexibility of this simulation, we also designed and included the reset function to set every element to the original status.

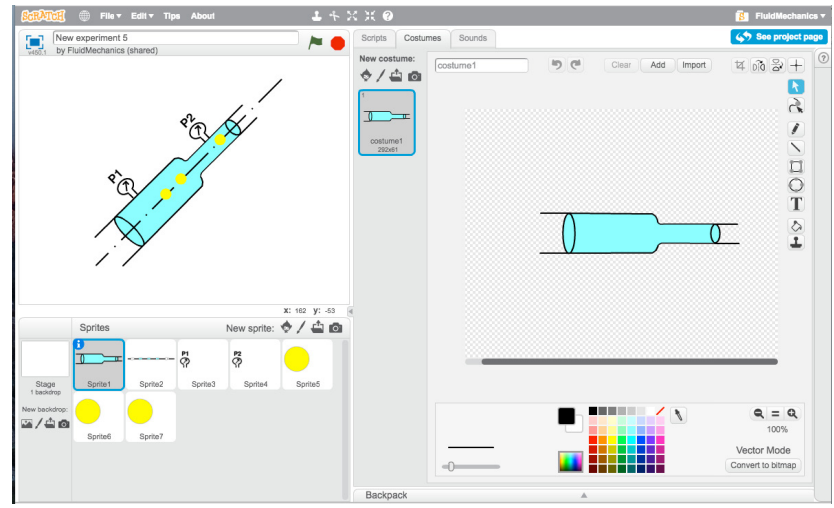

Fig. 11.Design for Inclined Pipe Bernoulli’s Equation Simulation 


\subsection{Building the Inclined Pipe Bernoulli's Equation}

When building the inclined pipe Bernoulli's equation simulation, the major challenge was the creation of the pipe and incorporating the velocity component. We spent some time on drawing the pipe for a better visualization. We set different speed control for each ball when they are going through different parts of the pipe so that students can easily tell the difference of the velocity. After several rounds of testing and resetting for the speed, we settled with the final version, as shown in Figure 11.

\section{Conclusions and Future Work}

Online learning is becoming an important part of higher education. Every year more and more higher education institutions are employing different technologies to offer their courses, degrees, and programs fully or partially online; which brought the challenge of how to offer engineering and technology courses in an online environment, especially when they have a laboratory component. This research paper provided a literature review of online, simulation-based, game-based and remote laboratories, and highlighted the incorporation of different technologies in different courses and laboratories. An online Applied Learning Fluid Mechanics course is examined and design and development of two online simulations using the SCRATCH platform is presented in this study. A set of example assignments that can be employed in the Applied Fluid Mechanics course along with possible ways to create additional examples are discussed.

\section{References}

[1] Fabregas,E., Farias, G., Dormido-Canto, S., Dormido, S., and Esquembre, F. (2011). "Developing a remote laboratory for engineering education" Computers \& Education 57, pp:1686-1697 https://doi.org/10.1016/j.compedu.2011.02.015

[2] Fiore, L. and Ratti, G. (2007)."Remote laboratory and animal behaviour: An interac-tive open field system", Computers \& Education 49, pp:1299-1307 https://doi.org/10.1016/j. compedu.2006.02.005

[3] Canfora, G., Daponte, P., and Rapuano, S. (2004). "Remotely accessible laboratory for electronic measurement teaching", Computer Standards \& Interfaces, 26,pp: 489-499 https://doi.org/10.1016/j.csi.2004.03.001

[4] Yeung, K. and Huang, J. (2003). "Development of a remote-access laboratory: a dc mo-tor control experiment" Computers in Industry 52, pp:305-311 https://doi.org/10.1016/S01663615(03)00133-7

[5] Esche, S.K.,Chassapis, C., Nazalewicz,J., and Hromin,D.J. (2002). "A Scalable System Architecture for Remote Experimentation", Proceedings of 32nd ASEE/IEEE Frontiers in Education Conference, November 6-9, Boston, MA https://doi.org/10.1109/FIE.2002.1157938

[6] Klein A. and Wozny,G., (2006). "Web based remote experiments for chemical engi-neering education The online distillation column", Trans IChemE, Part D, Education for Chemical Engineers, 1, pp:134 - 138 https://doi.org/10.1205/ece06015

[7] Jara, C.A., Candelas, F.A., Puente, S.T., and Torres, F. (2011). "Hands-on experiences of undergraduate students in Automatics and Robotics using a virtual and remote labora-tory", Computers \& Education 57, pp: 2451 - 2461 https://doi.org/10.1016/j.compedu. $\underline{2011.07 .003}$ 
[8] Prada,M.A., Fuertes, J.J., Alonso, S., Garcia,S., Dominguez,M. (2015), "Challenges and solutions in remote laboratories. Application to a remote laboratory of an electro - pneumatic classification cell", Computers \& Education 85, pp: 180-190 https://doi.org/10.1016/j.comp edu.2015.03.004

[9] Colwell, C., Scanlon, E., and Cooper, M. (2002). "Using remote laboratories to extend access to science and engineering", Computers \& Education 38, pp: 65-76 https://doi.org/10.1016/S0360-1315(01)00077-X

[10] Scanlon, E., Colwell, C., Cooper, M., and, DiPaolo,T. (2004). "Remote experiments, reenvisioning and re-thinking science learning", Computers \& Education 43, pp: 153 - 163 https://doi.org/10.1016/j.compedu.2003.12.010

[11] Corter, J.E., Esche, S. K., Chassapis, C., Ma, J., and Nickerson,J.V. (2011). "Process and learning outcomes from remotely-operated, simulated, and hands-on student la-boratories", Computers \& Education 57, pp: 2054 - 2067 https://doi.org/10.1016/j.compedu.2011. $\underline{04.009}$

[12] Ma, J. and Nickerson, J.V. (2006). "Hands-on, simulated, and Remote Laboratories: A Comparative Literature Review" ACM Computing Surveys, Vol.38, No.3, Article 7 https://doi.org/10.1145/1132960.1132961

[13] Tatli, Z. and Ayas, A. (2010). "Virtual laboratory applications in chemistry educa-tion", Social and Behavioral Sciences 9, pp: $938-942$

[14] Grimaldi, D and Rapuano, S. (2009). "Hardware and software to design virtual labora-tory for education in instrumentation and measurement", Measurement 42, pp: $485-493$ https://doi.org/10.1016/j.measurement.2008.09.003

[15] Shin, D., Yoon, E.S., Park, S.J., and Lee,E.S. (2000). "Web-based interactive virtual laboratory system for unit operations and process systems engineering education" Computers \& Chemical Engineering 24, pp: 1381 - 1385 https://doi.org/10.1016/S00981354(00)00365-3

[16] Guggisberg,M., Fornaro, P., Gyalog, T., and Burkhart, H. (2003). "An interdisciplinary virtual laboratory on nanoscience" Future Generation Computer Systems 19, pp: 133 - 141 https://doi.org/10.1016/S0167-739X(02)00107-3

[17] Quesnel,G., Duboz,R., Ramat, E. (2009). "The Virtual Laboratory Environment - An operational framework for multi-modeling, simulation and analysis of complex dy-namical systems" Simulation Modelling Practice and Theory 17, pp: $641-653$ https://doi.org/10.1016/j.simpat.2008.11.003

[18] Kara, A., Ozbek, M.E., Cagiltay, N.E., and Aydin,E. (2011). "Maintenance, sustaina-bility and extendibility in virtual and remote laboratories" Social and Behavioral Sci-ences 28, pp: 722 - 728 https://doi.org/10.1016/j.sbspro.2011.11.134

[19] Chen, S. (2010). "The view of scientific inquiry conveyed by simulation-based virtu-al laboratories", Computers \& Education 55, pp: 1123 - 1130 https://doi.org/10.1016/j.comp edu.2010.05.009

[20] Davidovitch, L., Parush A., and Shtub, A. (2006). "Simulation-based Learning in En-gineering Education: Performance and Transfer in Learning Project Management", Journal of Engineering Education, pp: 289-299 https://doi.org/10.1002/j.2168-9830.2006.tb00904.x

[21] Stephens, A.L., Clement, J.J. (2015). "Use of physics simulations in whole class and small group settings: Comparative case studies", Computers \& Education 86 pp: 137-156 https://doi.org/10.1016/j.compedu.2015.02.014

[22] Rafael, A.C., Bernardo,F., Ferreira, L. M., Rasteiro, M.G., and Teixeira,J.C., (2007). "Virtual Applications Using A Web Platform to Teach Chemical Engineering The Dis-tillation Case" Trans IChemE, Part D, Vol 2, Education for Chemical Engineers, pp: 20-28 https://doi.org/10.1205/ece06007

[23] Jara, C.A., Candelas, F.A., Torres, F., Dormido,S., Esquembre,F., Reinoso,O. (2009). "Realtime collaboration of virtual laboratories through the Internet" Computers \& Education 52, pp: $126-140$ https://doi.org/10.1016/j.compedu.2008.07.007 
[24] Dalgarno, B., Bishop,A.G., Adlong W., and Bedgood Jr., D.R. (2009). "Effectiveness of a Virtual Laboratory as a preparatory resource for Distance Education chemistry stu-dents" Computers \& Education 53, pp: 853-865 https://doi.org/10.1016/j.compedu.2009.05.005

[25] Brinson, J.R. (2015). "Learning outcome achievement in non-traditional (virtual and remote) versus traditional (hands-on) laboratories: A review of the empirical re-search" Computers \& Education 87, pp: 218 - 237 https://doi.org/10.1016/j.compedu.2015.07.003

[26] Lei,L., Liu, J., and Yang, X. (2012). "Research of the Remote Experiment System Based on Virtual Reality", Physics 24, pp: 1199-1206

[27] Nickerson, J.V., Corter,J.E., Esche, S.K., and Chassapis, C. (2007). "A model for eval-uating the effectiveness of remote engineering laboratories and simulations in educa-tion" Computers \& Education 49, pp: 708 - 725 https://doi.org/10.1016/j.compedu.2005.11.019

[28] Mott, R.L. and Untener, J.A. (2014). Applied Fluid Mechanics Seventh Edition, Pren-tice Hall

[29] Resnick,M., Maloney,J., Monroy-Hernández,A, Rusk, N., Eastmond,E., Brennan,K., Millner,A., Rosenbaum,E., Silver, J., Silverman,B., and Kafai, Y. (2009). "Scratch: pro-gramming for all" Communications of the ACM, 52(11), pp: 60-67 https://doi.org/10.1145/ 1592761.1592779

[30] https://scratch.mit.edu/ Scratch accessed on 03/26/2018

[31] Altuger-Genc, G., Han, Y. and Genc, Y. (2014), "Design and Development of Interac-tive Simulations to Support an Engineering Technology Course", Proceedings of the 2014 ASEE Annual Conference \& Exposition, Indianapolis, Indiana, June 15-18, 2014

[32] Altuger-Genc, G. (2015), "Virtual Simulations to Support an Applied Fluid Mechan-ics Course: A Pilot Implementation Overview", Proceedings of the 2015 ASEE An-nual Conference \& Exposition, Seattle, Washington, June 14-17, 2015 https://doi.org/10.18260/ p. 25041

[33] Saenz, J., Chacon, J., DeLaTorre, L., Visioli, A., and Dormido, S., (2015), "Open and LowCost Virtual and Remote Labs on Control Engineering" IEEE Access, 3 (2015), pp:805-814 https://doi.org/10.1109/ACCESS.2015.2442613

\section{$7 \quad$ Authors}

Dr. Gonca Altuger-Genc is an Assistant Professor at the School of Engineering Technology at Farmingdale State College. She received her B.S. degree in Mechanical Engineering from Eskisehir Osmangazi University, and received her Master's and $\mathrm{PhD}$ degrees in Mechanical Engineering from Stevens Institute of Technology.

Dr. Yue Han is an Assistant Professor at the Madden School of Business at Le Moyne College. She received her B.S. degree in Construction/Engineering Management from Central University of Finance and Economics, China. She received her M.S. degree in Project Management and Ph.D. degree in Information Systems from Stevens Institute of Technology.

Dr. Yegin Genc is an Assistant professor at the Seidenberg School of CSIS at Pace University. He received his B.S. degree in Mechanical Engineering from Istanbul Technical University, M.S. degree in Information Technology from University of Central Missouri and Ph.D. in Information Systems from Stevens Institute of Technology.

Article submitted 26 March 2018. Resubmitted 19 June 2018 and 08 October 2018. Final acceptance 09 October 2018. Final version published as submitted by the authors. 